\title{
Psicanálise e Assistência Social: 0 Sujeito entre a Demanda e o Desejo
}

\section{Psychoanalysis and Social Assistance: The Subject between Demand and Desire}

\section{Psicoanálisis y Asistencia Social: El Sujeto entre la Demanda y el Deseo}

\section{Thayane Bastos Moura Dias*}

Universidade Federal de São João del-Rei - UFSJ, São João del-Rei, Minas Gerais, Brasil

\section{Wilson Camilo Chaves**}

Universidade Federal de São João del-Rei - UFSJ, São João del-Rei, Minas Gerais, Brasil

\section{Fuad Kyrillos Neto***}

Universidade Federal de São João del-Rei - UFSJ, São João del-Rei, Minas Gerais, Brasil

\begin{abstract}
RESUMO
Refletimos aqui sobre as contribuições da Teoria Psicanalítica na especificidade da Política Socioassistencial. Trata-se de uma reflexão teórica orientada pelos pressupostos teórico-metodológicos da Psicanálise. A prerrogativa do cenário em questão é que o atendimento socioassistencial, voltado para a resolução das demandas dos usuários, seja pilar nessa instituição. O profissional de orientação psicanalítica, como técnico de referência do CRAS, deve ficar atento à demanda acerca dos direitos sociais. Esse é o objetivo primordial dessa instituição. No entanto, seu compromisso com a ética do desejo deve ser pautado na instituição. A diferenciação entre necessidade, demanda e desejo, orientada pela teoria psicanalítica, nos auxilia a diferenciar o que há de implícito na demanda socioassistencial que é endereçada ao CRAS. A afirmação de que há desejo, e não apenas necessidade no âmbito da Assistência Social, nos esclarece que existem sujeitos nessa instituição, e não simplesmente usuários. Uma prática institucional alicerçada na escuta se desdobra na consideração do sujeito no lugar do agente de um saber. Essa escuta propicia condições para o surgimento do sujeito em sua condição de desejante.

Palavras-chave: CRAS, psicanálise, sujeito, demanda, desejo.
\end{abstract}

\section{ABSTRACT}

This study reflects on the contributions of Psychoanalytic Theory in the specific nature of social assistance policy. This is a theoretical reflection guided by theoretical and methodological assumptions of psychoanalysis. 
The prerogative of the scenario in question is that the social assistance service, aimed at resolving the demands of users, either pillar that institution. Professional psychoanalytic while CRAS reference technician should be aware about the demand of social rights, this is the main objective of this institution. However, their commitment to the ethics of desire must be based. Differentiating between necessity, demand and desire, guided by psychoanalytic theory, helps us to distinguish what is implicit in the socialdemand that is addressed to CRAS. The claim that there is desire, not just need under the Social Assistance, explains to us that there are subjects that institution, not simply users. An institutional practice rooted in listening unfolds in consideration of the subject in place of the agent of knowledge. This listening provides conditions for the emergence of the subject in his desiring condition.

Keywords: CRAS, psychoanalysis, subject, demand, desire.

\begin{abstract}
RESUMEN
Este estudio refleja en las contribuciones de la teoría psicoanalítica en la naturaleza específica de la política de asistencia social. Se trata de una reflexión teórica guiado por supuestos teóricos y metodológicos de psicoanálisis. La prerrogativa del escenario en cuestión es el servicio Que ayuda social, destinado a resolver las demandas de los usuarios, ya sea pilar institución que. mientras psicoanalítica técnico profesional de referencia CRAS no debería ser consciente de la demanda de los derechos sociales, este es el objetivo principal de esta institución. Sin embargo, su compromiso con la ética del deseo debe basarse. Diferenciar entre necesidad, demanda y deseo, guiada por la teoría psicoanalítica, nos ayuda a distinguir lo que está implícito en la vida social demanda que se dirige a CRAS. Que la reclamación no es deseo, no sólo tiene bajo la Asistencia Social, nos explica Que hay temas institución Que, no simplemente a los usuarios. Una práctica institucional arraigada en la escucha se desarrolla en la consideración del tema en lugar del agente de conocimiento. Esta escucha proporciona las condiciones para la emergencia del sujeto en su condición deseante.
\end{abstract}

Palabras clave: CRAS, el psicoanálisis, sujeto, demanda, deseo.

As possíveis contribuições do campo PSI para a esfera da Assistência Social não constituem nenhuma novidade. No entanto, tal relação se mostra cada vez mais atual. Com o processo de redemocratização do Brasil, ainda em andamento, temos o direcionamento de Políticas Públicas que visam garantir a dignidade da pessoa humana, bem como a proteção aos direitos civis. Esse novo paradigma se reflete em mudanças graduais no que temos hoje como proposta de Políticas Públicas que assegurem a igualdade em relação ao acesso aos direitos. Podemos ilustrar a concretização desse novo horizonte em campos diversos. No âmbito da Assistência à Saúde Mental a Reforma Psiquiátrica marca o apontamento para uma perspectiva de tratamento que considere o público enquanto cidadão de direitos. $O$ Estatuto da Criança e do Adolescente (ECA) criado em 1990 instituiuse como Lei Federal no 8.069, preconizando a Doutrina da Proteção Integral, cujo marco é o reconhecimento das crianças e adolescentes brasileiros como sujeitos de direitos. No que tange à Assistência 
Social, essa mudança de paradigma se traduz no reconhecimento do dever do Estado enquanto assegurador de direitos. Nessa perspectiva, a criação do SUAS, bem como de seus equipamentos executivos - CRAS, CREAS e outros serviços - trazem consigo a necessidade do diálogo sobre os modos de se operar na Assistência Social na perspectiva do sujeito de direitos. Esse fato precisa ser discutido, fazendo também uma interpelação à psicanálise.

Nesta perspectiva, este trabalho se inscreve no contexto de uma reflexão teórica orientada pelos pressupostos teórico-metodológicos da Psicanálise, circunscrito ao espaço da psicanálise aplicada, no qual algumas características, propostas por Dunker (2013) estão presentes: recordação, isto é, um discurso que se orienta pela história e contingências que the é inerente; implicação, a produção de um discurso que se interroga eticamente sobre a experiência de estranhamento com a qual se defronta e, por fim, a transferência que se apresenta na disposição de articular um discurso em relação a uma suposição de saber que faça intenção de diálogo. A importância dos pensamentos de Freud e de Lacan se mostra na aposta em uma fecunda articulação entre psicanálise e outros campos, dado o caráter plural que tomaram as obras desses autores. Apostamos na possibilidade de interlocução entre os dois campos, pois como nos lembra Rinaldi (1996), a especialização de um saber em campos que não se comunicam entre si é um sintoma da crise do pensamento contemporâneo, o que pode ter como consequência a unilaterização do fazer em nosso cenário.

Ao longo desse artigo, pretendemos discutir as possíveis contribuições da teoria psicanalítica para o campo da Proteção Social Básica da Assistência Social, partindo do usuário do CRAS indo ao encontro do sujeito. Assim, a fim de expor nosso cenário enquanto objeto de pesquisa, faremos uma apresentação da instituição CRAS, uma breve análise do que é a demanda no contexto social, para enfim, tratarmos do que é a demanda com base em pressupostos psicanalíticos. Esse percurso teórico nos auxilia a diferenciar o que tem de implícito na demanda socioassistencial que é endereçada ao CRAS. Com isso, contextualizaremos o possível fazer do psicanalista nessa instituição.

Em 1910, Freud já manifestava sua preocupação a respeito do fazer do psicanalista fora dos moldes tradicionais da clínica em As Perspectivas Futuras da Terapêutica Psicanalítica, em que relata a importância do avanço do conhecimento e da técnica psicanalítica por meio de modificações e da ampliação desse trabalho à comunidade necessitada. Freud (1918/2006) retoma essa questão em seu pronunciamento no Quinto Congresso Psicanalítico em Budapeste, em Linhas de Progresso na Teoria psicanalítica, momento em que dá maior ênfase à importância do psicanalista pensar a realidade em que atua. Nesse sentido, discute o alcance do tratamento psicanalítico 
naquela época, pensando em uma "adaptação" da técnica psicanalítica a novas situações e da combinação da assistência mental com certo apoio material como possibilidade de trabalho. Nesse texto, Freud (1918/2006) manifesta sua preocupação com o lugar da psicanálise no âmbito social. Ele vislumbra a necessidade de aliar a psicanálise ao suporte material oferecido pelo Estado.

$\mathrm{Na}$ atualidade das palavras de Freud (1918/2006), constata-se que a atenção clínica, enquanto necessidade e direito, ultrapassa os limites dos serviços de saúde desdobrando-se também para o campo da Assistência Social. A necessidade de se repensar os aspectos teóricoclínicos da psicanálise para além dos moldes tradicionais dos consultórios também é uma marca contemporânea no pensamento freudiano. São duas apostas que se entrecruzam atualmente na concretização da ampliação da clínica psicanalítica em instituições públicas e/ou privadas. Contudo, em instituições que não se configuram na área da Saúde, como é o caso da Assistência Social, o lugar da psicanálise não está previsto, pois esse espaço ainda se mostra restrito à Psicologia Comunitária e Social. Isso pode ser constatado em uma verificação dos manuais para orientações técnicas do profissional com formação em Psicologia no campo da Assistência Social ${ }^{1}$. O lugar da psicanálise nessas instituições tem que ser inventado.

No Brasil, temos um apanhado de pesquisas que buscam articular a prática e a teoria psicanalítica em contextos institucionais no âmbito das Políticas Públicas, ainda que recentes. Podemos citar alguns trabalhos mais próximos no tempo, como os de Tenório (1999), Alberti e Figueiredo (2006), Figueiredo (2011) e Andrade Filha (2013) no contexto da Política de Assistência à Saúde Mental. Tais pesquisas, dentre inúmeras outras tão quão valiosas, são atravessadas por um esforço de articulação de saberes que contribuem para o processo da Reforma Psiquiátrica, introduzindo a diferença a partir do discurso psicanalítico.

No que se refere a temas laterais à Assistência Social, tal articulação se dá ainda de maneira tímida. Podemos citar pesquisadores como Maria Cristina Candal Poli, Tânia Ferreira, Andrea Guerra, Doris Rinaldi e Mirian Debieux Rosa. Mais especificamente ligados à Política de Assistência Social, encontramos: Em busca do sujeito perdido: a psicanálise na assistência social, limites e possibilidades, de Scarparo (2008); O praticante de psicanálise no Centro de Referência da Assistência Social - CRAS. A intervenção retificadora e outras questões, de Mariano (2011) e Mal-estar na cultura e suas incidências na clínica em contexto de exclusão, de Susin (2012). Esses autores estão implicados na tarefa de abordar situações de miserabilidade e carência a partir da teoria psicanalítica. O diálogo com as ideias e contribuições desses autores foi fundamental para as proposições presentes nesta pesquisa ainda que cada um deles tenha traçado seu 
percurso a partir da especificidade de sua prática de maneira singular. A presença dos psicanalistas nas instituições públicas de Assistência Social tem como consequência a ampliação do âmbito da prática psicanalítica, seguindo a aposta de Freud em Linhas de Progresso da Terapia Psicanalítica (1918/2006). Uma vez presente, faz-se necessário à psicanálise afirmar sua especificidade sustentando sua ética a respeito do fazer preconizado pela Política Pública de Assistência Social.

\section{A instituição CRAS - A Casa das Famílias}

Para melhor entendermos a especificidade da atuação do profissional com formação em Psicologia no âmbito da Política Nacional de Assistência Social (doravante PNAS) e, particularmente, no Centro de Referência da Assistência Social (CRAS), faremos uma breve explanação desse cenário enquanto Política Pública Nacional até a sua caracterização no município. Ao realizarmos tal percurso, almejamos fazer uma análise de tal política e de sua dinâmica municipal, tendo em vista que uma de suas diretrizes é a descentralização políticoadministrativa das ações.

Apesar de existir há mais de uma década enquanto sistema estruturado, a PNAS ainda está sendo consolidada e é cada vez mais discutida. Assim, entender sua trajetória de implementação com o processo de redemocratização do Brasil, principalmente com a promulgação da Constituição Federal (CF) em 1988, nos instrumentaliza a enfrentar seus próprios desafios. Para tanto, é imprescindível fazermos um breve percurso dos marcos normativos que deram novo status à assistência social no Brasil, de modo a assegurá-la como um direito do cidadão e um dever do Estado, deixando de ser considerada por uma perspectiva assistencialista que geram ações pontuais e segmentadas. É nesse sentido que tal política parte das ações integradas na perspectiva da intersetorialidade, logo, não cabe à assistência social substituir outras políticas, pois a mesma é utilizada como uma espécie de "atalho" ao acesso às demais políticas.

As garantias geradas pela CF de 1988 em relação à Assistência Social tiveram implicações fundamentais, uma vez que com a vigência da Lei Orgânica de Assistência Social (LOAS), passa a ser reconhecida enquanto Política Pública. A aprovação do Sistema Único de Assistência Social (SUAS), em 2005, marca a unificação das ações de Assistência Social no âmbito nacional em dois níveis: Proteção Social Básica e Proteção Social Especial.

A Proteção Social Básica, prioridade na assistência social, objetiva prevenir situações de risco por meio dos serviços de fortalecimento de vínculos familiares e comunitários que se dão por ações como: 
acolhimento, grupos de convivência, oficinas com famílias, oficinas socioeducativas, ações comunitárias, ações particularizadas e encaminhamentos. Esses serviços são destinados à população que vive em situação de vulnerabilidade social decorrente da pobreza, da privação (ausência de renda, precário ou nulo acesso aos serviços públicos, dentre outros) e/ou, da fragilização de vínculos afetivos relacionais e de pertencimento social (discriminações etárias, étnicas, de gênero ou por deficiências, dentre outras). Os serviços da Proteção Social Básica são executados de forma direta nos CRAS e em outras unidades básicas e públicas de Assistência Social, bem como de forma indireta nas entidades e em organizações de Assistência Social da área de abrangência dos CRAS (Brasil, 2004). O CRAS é uma unidade pública de base territorial, localizado em áreas com maior índice de vulnerabilidade e de risco social do município. Cabe a essa instituição executar serviços de Proteção Social Básica, organizar e coordenar a rede de serviços socioassistenciais locais da política de Assistência Social.

A Proteção Social Especial tem como objetivos contribuir para a reconstrução de vínculos familiares e comunitários, a defesa de direito, o fortalecimento das potencialidades e aquisições e a proteção de famílias e de indivíduos para o enfrentamento das situações de ameaça ou de violação de direitos, subdividindo-se em Média e Alta Complexidade. O que diferencia os níveis de complexidade é a existência ou não de vínculos do sujeito com a família e com a comunidade, sendo que quando há violação de direitos sem rompimento de vínculos no caso, ele se configura como média complexidade e quando há rompimento de laços como alta complexidade. As ações da Proteção Social Especial de Média Complexidade se dão por meio do Centro de Referência Especializado da Assistência Social (CREAS), o qual acompanha pessoas em situação de risco e de vulnerabilidade social que tiveram seus direitos já violados, sendo elas: adolescentes infratores, pessoas que sofreram violação dos direitos, seja por distinção de cor, etnia, gênero, crença, idade, orientação sexual etc. Já a Proteção Social Especial de Alta Complexidade oferta serviços que objetivam assegurar a acolhida aos indivíduos e às famílias afastadas do núcleo familiar e comunitário com serviços de acolhimento institucional, como os Abrigos Institucionais, as Casas Lares e o Sistema de Abrigamento Temporário para hospedagem provisória em casos de desabrigamento por desastres (enchentes e deslizamentos), dentre outros.

As ações em Assistência Social, ainda que estejam articuladas com o alívio imediato da extrema pobreza, têm como objetivo pilar o desenvolvimento da autonomia das famílias em situação de risco e em vulnerabilidade social. Diante do exposto, compreendemos que vínculo do profissional com a comunidade, com as famílias 
referenciadas e com os sujeitos é fator fundamental para o desenvolvimento e para consolidação da política no âmbito municipal, já que se trata de um trabalho continuado que tem resultados em longo prazo e que depende diretamente da forma como os operadores da política atuam no âmbito municipal.

Tanto o CRAS como o CREAS contam com uma equipe mínima constituída por dois técnicos de nível médio e dois técnicos de nível superior, sendo um Assistente Social e outro Psicólogo. Contudo a composição da equipe de referência varia de acordo com o número de famílias referenciadas e como o tamanho do município. O crescimento do número de profissionais com formação em Psicologia inseridos nesses serviços é notável, uma vez que o SUAS prevê a inserção dos mesmos para comporem a equipe mínima dos CRAS e CREAS. Desde o ano de 2011 essa composição de referência passa a ser obrigatória e não mais preferencial (CNAS, 2011). Tal obrigatoriedade sinaliza a necessidade de pensarmos os parâmetros teóricos que subsidiam a atuação do profissional em Psicologia no CRAS.

\section{A atuação do profissional em Psicologia no CRAS}

De acordo com as orientações técnicas do SUAS (Brasil, 2005), os técnicos de nível superior que trabalham na Proteção Social Básica (Assistente Social e Psicólogo) recebem as mesmas atribuições profissionais, sendo elas: executar procedimentos profissionais para escuta qualificada individual ou em grupo, identificar necessidades e orientar indivíduos e famílias; articular serviços e recursos para atendimento, encaminhamento e acompanhamento das famílias e indivíduos; trabalhar em equipe; produzir relatórios e documentos necessários ao serviço; desenvolver atividades socioeducativas de apoio, acolhida, reflexão e participação, que visem o fortalecimento familiar e a convivência comunitária (Brasil, 2005).

No CRAS, o Serviço de Proteção Integral à Família - PAIF constitui o alicerce das ações a serem desenvolvidas, com base no diagnóstico de que a vulnerabilidade e o risco social são multideterminados, ou seja, estar vulnerável e em risco são situações que extrapolam a dimensão meramente econômica, o que exige intervenções que perpassem aspectos objetivos e subjetivos do público-alvo. Compreende-se os aspectos subjetivos ali presentes como:

O espaço íntimo constituído pelas marcas singulares adquiridas no processo de formação individual, bem como pelas crenças e valores compartilhados na dimensão cultural, que acabam por constituir a experiência histórica e coletiva dos grupos e populações em um dado território (Brasil, 2012b, p. 19). 
Há o reconhecimento de que, é por meio da subjetividade que é possível se relacionar, criar vínculos. Isso nos interessa, tendo em vista que os serviços oferecidos na Proteção Social Básica são direcionados pelo PAIF, que tem como principal objetivo o trabalho com o fortalecimento de vínculos. A execução das ações do PAIF é de responsabilidade direta dos profissionais de nível superior que compõem a equipe técnica do CRAS, sob supervisão do coordenador dessa instituição, portanto, incumbência do profissional em Psicologia.

Por meio do PAIF, a atuação do profissional psi visa apontar alternativas para o fortalecimento dos vínculos familiar e comunitário da população que se encontra em situação de vulnerabilidade social, bem como a articulação dos recursos subjetivos para o fortalecimento desses vínculos. Cabe ressaltar aqui que uma das prerrogativas que regem o PAIF é a de não desenvolver ações de caráter terapêutico, compreendidas como práticas psicoterapêuticas, psicodiagnósticas e psicopedagógicas, ou quaisquer outras modalidades com fins terapêuticos (Brasil, 2012b). Todavia, pressupõe-se que os técnicos possuam capacidade para escuta qualificada individual e em grupo (Brasil, 2009). Postular que as práticas clínicas não compõem o rol de ações do PAIF não é negar aos profissionais dos CRAS com formação em Psicologia de utilizarem seus conhecimentos para atender e acompanhar as famílias por meio de uma escuta dos aspectos subjetivos envolvidos nas situações de vulnerabilidades vivenciadas por elas.

Ao profissional da Psicologia orienta-se intervir no sentido de: a) compreender os processos subjetivos que contribuem para a incidência de vulnerabilidade e risco social de famílias e indivíduos; b) contribuir para a prevenção de situações que possam gerar ruptura dos vínculos familiares e comunitários e c) fomentar o desenvolvimento da autonomia dos usuários do CRAS. Com isso, a subjetividade é levada em consideração em três dimensões que estão interligadas: como ponto de partida para se compreender os fatores que levam à vulnerabilidade; para se trabalhar a prevenção dos fatores de risco e para se ter meios de construir um projeto emancipatório dos usuários. Orienta-se, ainda, que os casos com demanda de atendimento psicológico devem ser encaminhados para outros serviços da rede intersetorial (Brasil, 2009). Tais orientações são plausíveis, pois consideram os objetivos da PNAS, entretanto, percebemos a necessidade de uma escuta, muitas vezes de caráter clínico, na Proteção Social Básica, principalmente se levarmos em conta que a expressão subjetiva é condição para o sucesso na construção da autonomia.

Deparamo-nos aqui com uma questão crucial para o profissional em Psicologia que atua nesse cenário. Se as intervenções desse técnico devem abarcar primariamente a compreensão dos determinantes 
exclusivos que levam alguns indivíduos a situações de fragilidade social, seja para preveni-las ou para superá-las, como esses profissionais terão acesso a esses fatores, se não pela escuta dos atores de sua própria história?

A prerrogativa desse cenário é que o atendimento socioassistencial, voltado para resolução das demandas dos usuários da assistência social, seja pilar nessa instituição. De fato, acolher o sujeito que chega até o CRAS e direcioná-lo ao acesso aos seus direitos é fundamental para a saída da situação de extrema privação material e de exclusão social em que eles se encontram. No entanto, para além de ouvir e acolher a demanda social que nos é apresentada, expressa em necessidades materiais urgentes, a perspectiva psicanalítica propõe uma escuta do discurso, como possibilidade de situar o sujeito (\$) 2 em relação à sua questão. Escuta, articulação dos fatores subjetivos, condução do processo grupal e muitos outros conhecimentos e práticas do campo psi estão ali presentes. Se queremos aprofundar a discussão sobre a importância do campo psi no SUAS, é importante reconhecer que a escuta atravessa o fazer do psicólogo/psicanalista ali, ainda que não seja na forma de psicoterapia/análise propriamente ditas.

\section{A demanda no contexto socioassistencial}

Atualmente, podemos contextualizar novas formas de demanda social advindas dos avanços em relação à garantia dos direitos socioassistenciais para além dos direitos relativos à garantia de sobrevivência. A partir de marcos legais e da criação de novas secretarias, como a Secretaria dos Direitos Humanos, Secretaria Especial de Direitos para Mulheres, Políticas de Promoção da Igualdade Racial, gradualmente vemos o progresso em relação aos direitos no Brasil. A título de ilustração, o Estatuto do Idoso, o Estatuto da Criança e do Adolescente, a Lei Maria da Penha e, mais recentemente, a Lei menino Bernardo, mesmo que ainda gerem controvérsias e precisem de constante debate e aprimoramento, marcam um novo horizonte no que tange à Políticas Públicas que visam a garantia dos direitos.

Quando o sujeito chega à instituição CRAS com essas demandas, sua posição é a do sujeito de direitos e cabe ao técnico fazer o acolhimento dessa queixa. A acolhida é o contato inicial de um sujeito ou de uma família com o SUAS. Esse contato se dá, na maioria dos casos, por intermédio do CRAS, porta de entrada da Política de Assistência Social. O mecanismo de acolhimento se traduz na escuta das necessidades e demandas trazidas pelo público, bem como na oferta de informações sobre as ações oferecidas na rede socioassistencial e demais setores. Nesse momento inicial o 
profissional deve articular os significados das demandas que são endereçadas à instituição, como é proposto pelo MDS:

A acolhida é uma etapa em que se deve coletar informações sobre a vida familiar e comunitária das famílias e sobre o território, sendo importante considerar não só os aspectos objetivos, concretos, tais como a situação socioeconômica vivenciada, mas também a subjetividade das famílias, suas crenças, valores, formas de comunicação e expectativas em relação ao Serviço (Brasil, 2012c, p. 18).

No âmbito da Assistência Social, o termo demanda é amplamente utilizado. Seu sentido mais recorrente está conjugado ao de necessidade - das necessidades sociais básicas para sobrevivência. Quando o indivíduo (demandante, cidadão, usuário) expõe à instituição suas necessidades, ele tem a pretensão de receber uma ação socioassistencial que as supra. Demandar é uma ação que é dirigida a alguém. Exigir, solicitar, reclamar, procurar, perguntar, dirigir-se à, caminhar para, são possíveis sinônimos para esse ato.

No contexto do CRAS, a demanda pode ser dirigida aos técnicos de referência ou identificada por eles. São dois movimentos diferentes, embora tenham a posteriori as mesmas ações previstas para suprimila. Como define o Dicionário de Termos Técnicos da Assistência Social, demanda é a "manifestação de necessidades, apresentadas explicitamente pelo usuário ou identificadas pelo técnico, que exigem intervenções de natureza socioassistencial" (Belo Horizonte, 2007, p. 33).

A situação de risco social em que o usuário se encontra no momento da queixa pode variar de condições circunstanciais ou estruturais. Recebemos como demandas conjunturais, por exemplo, a falta de alimentos, de recursos para arcar com gastos de óbitos familiares, o risco de moradia em casos de calamidades, entre outros, que são demandas que se configuram como casos de direito aos benefícios eventuais. Outras situações de vulnerabilidade social podem se enquadrar em casos que não são momentâneos, em que há ocorrência intergeracional da situação de extrema pobreza. Esses casos demandam adesão aos programas e serviços de longo prazo em alguns casos, até que o usuário consiga adquirir autonomia e se desligue do programa - como o Programa Bolsa Família, o Minha Casa Minha Vida, dentre outros.

Para além da demanda em seu aspecto material, percebemos por meio da nossa escuta, a insistência de demandas que não se enquadram nesse aspecto, que denunciam impasses de ordem subjetiva. Podemos colocar como exemplos, dificuldades na separação conjugal, mesmo em casos de violência familiar; dificuldades em se haver com as consequências da adicção, mesmo 
com ameaça de perda da guarda dos filhos; não aceitação de uso de métodos contraceptivos, mesmo com risco de iminência de mais um filho que não terá o que comer, entre outros.

Mariano (2011) aponta que a demanda endereçada à instituição CRAS pode ser caracterizada em três aspectos distintos, que nos auxilia na escuta da demanda e em seu possível desfecho. Pode ser que a demanda seja uma demanda social de enunciado direto, momento em que o sujeito vai à instituição com uma reivindicação clara de acesso aos seus direitos. Outra possibilidade é a demanda social de cunho subjetivo, onde há reivindicação de direitos que cobre uma questão subjetiva e ainda, demanda subjetiva de enunciado direto, onde explicitamente a demanda se caracteriza como um pedido de ajuda para si.

A partir dessa distinção o que pode ser feito pelo profissional sob orientação psicanalítica é avançar no discurso institucional que pressupõe um sujeito totalizado (S) a partir da garantia dos direitos, como se o que the faltasse fosse somente dessa ordem. As demandas nem sempre estão diretamente relacionadas aos direitos sociais, pois o sujeito é, antes de tudo, sujeito de desejo. Por este viés o psicanalista assume o compromisso de fazer emergir nesse cenário a articulação entre os direitos socioassistenciais com o que há de particular no indivíduo.

\section{A noção de demanda na teoria psicanalítica}

Não podemos deixar de considerar aqui a dimensão elementar relativa à situação de desamparo humano em busca do estado original de completude e de satisfação. Frente a essa condição, restanos demandar cuidados, alimento, atenção, amparo, amor. O bebê chora, grita, faz gestos, com o intuito de dirigir sua demanda a um objeto que o satisfaça. Seu cuidador receberá seu pedido ofertando a ele uma ação específica que sacie sua necessidade. Mas a situação de desamparo inerente ao homem permanece e a demanda endereçada ao outro não cessa, ela circula.

A demanda, quando ultrapassa o campo da necessidade, se faz como um pedido de restituição do objeto outrora perdido no estado original de satisfação. O desejo inconsciente para Freud, de acordo com Laplanche e Pontalis (2001, p. 114), realiza-se na tentativa de restabelecer os sinais ligados às primeiras vivências de satisfação. A imagem mnêmica, produzida na primeira experiência de satisfação, é insistente e se reproduz, quando há excitação provinda da necessidade. Quando a necessidade reaparece, produz-se, então, uma moção psíquica que tende a reinvestir nessa imagem, buscando vivenciar novamente a situação primeira de satisfação. É essa moção que Freud chama de desejo. Num movimento dinâmico, o desejo 
emerge com o reinvestimento psíquico do traço mnêmico da primeira experiência de satisfação, na tentativa de reconstituí-la.

No centro do discurso psicanalítico, o desejo ganha corpo e destaque. Todavia, aqui não nos referimos ao desejo naturalizado, como é articulado no campo da biologia e apropriado em outros campos do conhecimento. Não estamos tratando aqui do desejo enquanto satisfação pontual de uma necessidade, relação que foi identificada anteriormente na Política de Assistência Social, mas do desejo lançado na ordem simbólica, não sem consequências para a nossa questão em debate.

Necessidade e demanda, são âncoras para o desejo. Temos alguns elementos para iniciar uma possível diferenciação entre necessidadedemanda-desejo. A necessidade, advinda de um estado de tensão interna, visa um objeto específico e uma ação específica tem êxito em satisfazê-la. Sendo assim, a necessidade tem objeto na realidade, o desejo não o tem. O desejo é indissociável aos traços mnêmicos produzidos pela satisfação da necessidade e encontra sua realização na tradução alucinatória da satisfação, ou seja, sua realização está no âmbito da realidade psíquica.

Em O Seminário, Livro 1: Os escritos técnicos de Freud, Lacan (19531954/2009) afirma que o desejo se constitui como no movimento de báscula (no francês bascule, balança decimal), numa espécie de troca com o outro, já que é por esse outro que a criança exprime o desejo e, invertido no outro, que ele é reconhecido. No Seminário, Livro 5, As formações do inconsciente, Lacan (1957-1958/1999) explicita a relação do significante com o desejo através de três fórmulas ou três momentos que se complementam. Na primeira fórmula do desejo ${ }^{3}$, é o outro (a), enquanto nosso semelhante, o pivô dessa relação. 0 desejo (d) que está na primeira extremidade vai ao encontro da outra extremidade, que é o eu $(\mathrm{m})$. A configuração do desejo dá-se pela relação do sujeito (\$) com o seu semelhante, o outro (a). Dessa forma, a constituição do desejo do sujeito faz-se, num primeiro momento, mediada pela relação imaginária com o outro (a), por algo no outro que tem significado para o sujeito com o qual ele se identifica.

A criança, antes mesmo de nascer, já tem um universo linguístico organizado à sua espera. Seu nome já pode está definido, sua língua materna já está estabelecida. Quando nasce, deve comunicar-se, ainda que não verbalmente, a fim de que alguém atue para satisfazer suas necessidades. Nesse estádio, do choro, do grito, sua comunicação é interpretada pelo outro, que garante uma ação específica. Assim, a solicitação cada vez mais se adapta à interpretação desse outro. É o outro quem dá sentido e nomeia a necessidade. Mais tarde, a criança aprende a língua falada pelos pais para manifestar seu desejo. Agora os pais não têm que interpretar 0 que ela quer, ela diz! Não obstante, seus desejos agora expressos em 
palavras são articulados ainda por meio desse outro. Não há garantias de que as palavras utilizadas para tal correspondam necessariamente às suas demandas. $O$ desejo é moldado pela língua aprendida e, para além da necessidade, seu surgimento pressupõe a presença do Outro.

Lacan (1957-1958/1999) propõe a segunda fórmula do desejo, que retrata a relação do desejo com a palavra, através da demanda. Aqui, é o Outro (A) enquanto o lugar da sede dos significantes que estrutura a relação do desejo com o Ideal do eu. Os (A) expressa o que no Outro (A) toma valor de significado para o sujeito com a ajuda do significante (s). Qualquer identificação com as insígnias do Outro (A) depende da demanda (D) e da relação do Outro (A) com o desejo (d). É através desses signos que se produz o ideal do eu (I), instância psíquica que advém no momento do declínio do Édipo e que resulta num processo de cristalização narcísica e de identificações com modelos ideais. Nesse sentido, só existe acesso à identificação do Ideal do eu (I) depois que há o Outro (A) ${ }^{4}$.

O desejo da criança, a princípio, é indissociável do Outro. O desejo passa pela satisfação da necessidade nesse direcionamento ao Outro, que o nomeia e o transforma em demanda de amor, ou seja, demanda de ocupar um lugar no desejo do Outro. A demanda é expressão do desejo, mas também se configura para além da satisfação da necessidade, há um "a mais" que Lacan chama de demanda de amor, pois ainda que indique um objeto de necessidade, é demanda de amor na qual a criança deseja ser o único objeto de desejo do Outro que o satisfaz. Como afirma Lacan (1957$1958 / 1999$, p. 407), "é no lugar que o sujeito procura articular seu desejo que ele depara com o desejo do Outro como tal". O desejo do Outro se encontra com o desejo de reconstituição da satisfação originária, momento em que houve, de fato, satisfação. Com outras experiências de satisfação, a mediação da demanda confronta a criança com a dimensão da perda. Há algo da satisfação que é da ordem do impossível de ser revivido e, com isso, o desejo fica suspenso em busca do reencontro de algo que foi perdido. Com a mediação da linguagem, é introduzido um conflito entre o que é desejado e o que está implicado na demanda (Dor, 1989).

Ainda no Seminário, Livro 5: As formações do inconsciente, Lacan (1957-1958/1999) coloca que o desejo está intimamente ligado a uma marca, uma insígnia, um traço, que na universalidade do complexo de castração deixa sua especificidade. Segundo ele, é na passagem pela Lei da castração que se inscreve no sujeito o significante que sustenta a relação castradora, com o qual o sujeito se identifica e, ao mesmo tempo, o qual direciona sua relação com a interdição. Lacan revela assim, o caráter significante da castração e sua relação com o desejo. É enquanto o sujeito (\$) se constitui e se situa em relação ao significante, que se produz nele uma ruptura, 
uma divisão onde se encontra a tensão do desejo (Lacan, 19571958/1999).

O lugar que o Outro ocupa na relação do sujeito com o seu desejo é que o estrutura na linguagem, já que o Outro, que nos referencia no campo da fala, é o lugar do "tesouro dos significantes", ou seja, onde se situa a cadeia de significantes. Após esse processo, o sujeito se depara com o desejo do Outro, que é marcado pelo significante fálico, significante da falta. Ao passo que esse Outro é barrado, o sujeito se reconhece enquanto castrado. O desejo, então se estrutura pela alienação na linguagem, no desejo do Outro, pela interposição da lei do Édipo e à Lei da castração. Esse Outro que é o lugar da fala, portanto, é também o lugar da falta. A terceira fórmula do desejo ${ }^{5}$ exprime o momento da interação do sujeito desejante com 0 significante fálico em si. o $\Delta$ é o eixo que impulsiona o sujeito na relação com o significante, é o que coloca o caráter enigmático dessa relação, aquilo sobre o qual nos fazemos questão. A fórmula aponta que o $S\left({ }^{\boldsymbol{A}}\right)$, o significante (S) do Outro barrado ( ${ }^{\boldsymbol{A}}$ ) é consequência do falo $(\phi)$, ou seja, o falo $(\phi)$ é o significante que introduz no Outro barrado ( ${ }^{\boldsymbol{A}}$ ) algo de novo.

O objeto do desejo, na teoria psicanalítica, é uma falta e não algo que propiciará a satisfação (Lacan, 1964/1988). A estrutura do desejo é exatamente esse movimento da busca de algo que por si é inacessível, é esse movimento que o torna incessante. O desejo é a busca pelo objeto perdido na experiência de satisfação original, cuja presença é marcada pela falta. Nas palavras de Garcia-Roza (1984/2007, p. 145): "O desejo é a nostalgia do objeto perdido". O que o move é estranho paradoxo, justamente a falta. Isso quer dizer que o desejo não tem objeto como tal, ele tem causa, possui objeto que causa desejo, o objeto a responsável pelo advento do desejo. 0 que Lacan (1964/1988) chama de objeto a, objeto perdido, causa do desejo. Nessa perspectiva, quando consideramos o objeto do desejo enquanto falta, não podemos falar de uma plena satisfação daquele, mas sim de uma espécie de contorno com base na busca incessante de satisfação de maneira circular.

No Seminário, Livro 7: A ética da psicanálise, Lacan (19591960/2008) nos lembra que a resposta psicanalítica para a demanda que nos é endereçada deve ser uma resposta atenta, que não adultere o sentido inconsciente dessa demanda. Já que o desejo é aquilo que se coloca para além da demanda, nossa atenção deve estar voltada justamente para a falta que move o desejo que nela está implícito. É na modificação da mesma que há possibilidade de um resto que é o desejo, o qual pode se manifestar como algo inominável.

Dizer que o desejo ganha destaque em nossa experiência não é o mesmo que usá-lo como justificativa para todas as ações do sujeito 
indiscriminadamente, visto que a noção de desejo em Freud e em Lacan não deixa de estar relacionada à Lei. Não se trata da lei enquanto um conjunto de normas nos quais estamos inseridos e somos submetidos, mas da Lei da castração, fundamentada no que há de inalcançável na plena satisfação do desejo. Desejo e Lei são, ainda que conflituosamente, correlatos. Essa Lei, mesmo sendo afirmada como universal, é o que articula a estrutura do desejo, é ela que funda algo de particular no sujeito (Rinaldi, 1996). Ainda consoante Rinaldi (1996), é nesse sentido que se pode pensar na ética que orienta a experiência psicanalítica como uma ética do desejo que possibilita o surgimento do especial. A prática psicanalítica, ao se sustentar por meio dessa ética, tem como finalidade fazer aparecer o desejo singular de cada um. Agiste em conformidade com o seu desejo? é a questão que Lacan propõe como "postulado ético" a ser sustentado no contexto da prática psicanalítica, em que aparecem desejo e ação (Rinaldi, 1996) e a possível implicação do sujeito naquilo que ele mesmo desejou e escolheu.

Lacan discute ainda que a demanda que é endereçada ao analista toma forma de demanda de felicidade, ora colocada como possibilidade de resposta ao sujeito suposto saber - o analista. $O$ desejo, que tomamos como questão para o nosso debate, pode tornar-se limitado aos serviços de bens pela tendência à mudança de objeto - articulação inconsciente de uma sucessão de significantes que se constitui numa alienação fundamental. Para Lacan, a mudança de objeto dá-se pela metonímia do discurso da demanda e essa questão não é circunstancial para nós. Em meio às mais variadas formas de objetos de desejo que são oferecidos pelo mercado, os serviços de bens que são ofertados para satisfação das necessidades dos homens no campo da política também tomam forma de objeto. É nesse ponto que o imperativo de felicidade é aproximado ao campo da política por Lacan. Essa aproximação é colocada no âmbito da polarização do que é singular e do que é universal, como cita: "Não poderia haver satisfação de ninguém fora da satisfação de todos" (Lacan, 1957-1958/1999, p. 342). É essa demanda que o analista se oferece a receber e pontuar.

\section{À guisa de conclusão}

A implementação da instituição CRAS em todo o território nacional é uma ação estratégica para a garantia dos direitos socioassistenciais em uma ampla perspectiva de prevenção do rompimento de vínculos familiares e comunitários com ênfase no fortalecimento desses vínculos para enfrentamento da vulnerabilidade social no Brasil. Dentro dessa perspectiva, cabe ao profissional em Psicologia intervir 
nos aspectos subjetivos que determinam a situação de risco social das famílias/sujeitos. Diante desse enunciado, voltamos ao que se fez como questão nesta prática: interrogar o campo da experiência como colocou Lacan (1964/1988) em O Seminário, Livro 11: Os Quatro Conceitos Fundamentais da Psicanálise. Como operar, então, a partir da orientação psicanalítica, em um plano universal que prevê o acesso de todos de forma igualitária? O profissional em Psicologia que atua no CRAS é chamado a apontar alternativas de trabalho que visem à autonomia do público-alvo a partir de um plano de ação que parte do pressuposto que suas demandas são exclusivamente socioassistenciais. A Psicanálise, ao interrogar essa experiência, anuncia a necessidade da presença de um interlocutor que faça aparecer o desejo desses sujeitos.

Interrogar o campo da experiência a partir da nossa orientação diz do questionamento sobre em que condições um acontecimento é relevante, do ponto de vista clínico, para interrogar a teoria psicanalítica, como aponta Dunker (2013, p. 63). A condição que foi apontada aqui foi de que a demanda que é endereçada ao CRAS está intimamente articulada ao desejo do sujeito; ou seja, que a esse acontecimento se possa aplicar a hipótese do inconsciente e/ou suas possíveis incidências, de maneira que uma possível posição na pesquisa em Psicanálise vincula a hipótese do inconsciente ao contexto em que ele se aplica. Ao afirmarmos esse vínculo, foi introduzida a hipótese do inconsciente em um contexto no qual ela não está prevista, fora da situação tradicionalmente clínica.

Quando escutamos psicanaliticamente a demanda que é endereçada ao CRAS, podemos diferenciar o que o sujeito apresenta como questão: o seu desejo. Sabemos que a demanda endereça o pedido de restituição do objeto perdido na primeira experiência de satisfação, de forma que tal objeto nunca será plenamente alcançado. Em O Seminário, Livro 7: A ética da psicanálise, Lacan (1958[1960]/2008) assevera que a psicanálise não deve seguir a política da felicidade ou o que ele denominou de serviço dos bens. $O$ que temos no plano socioassistencial é que o ordenamento do serviço dos bens nem sempre vai ao encontro do homem com o seu desejo. Essa é a denúncia de Lacan ao criticar a associação da Psicanálise a qualquer adaptação ao sistema social. A garantia de bem-estar no plano da política socioassistencial tem um furo ao desconsiderar que o ordenamento dos serviços dos bens implica renúncias quando olhamos para a relação do sujeito com o seu desejo.

Acreditamos que por meio desse percurso podemos explicitar a dimensão constituinte do desejo vinculado a uma falta real de objeto, que emerge no contexto do CRAS sob a forma de demanda socioassistencial. A orientação que seguimos, se levarmos em consideração a distinção crucial entre necessidade-demanda-desejo, é que a demanda deve ser interpretada. Lacan (1958/1998) em $A$ 
direção do tratamento e os princípios de seu poder alerta-nos acerca do lugar que a interpretação ocupa no fazer psicanalítico. Segundo ele, nem toda intervenção verbal, bem como nem toda resposta à demanda, diz fielmente de uma interpretação analítica. Esse cuidado deve ser tomado aqui, quando a nós são endereçadas demandas acompanhadas de anseio por reposta imediata. Sobre o imediatismo, Lacan (1958/1998, p. 599) refuta: "a interpretação introduz uma resolução de fechamento a uma incompletude que, no entanto, só se realiza a posteriori". Ainda consoante esse autor, cabe ao analista sustentar a demanda, para que os significantes de sua frustração reapareçam e se articulem.

Dizer que há desejo, e não apenas necessidade no âmbito da Assistência Social, esclarece a nós que existem sujeitos nessa instituição, e não simplesmente usuários. Podemos dizer também que a demanda primeira do sujeito é de ser reconhecido no seu desejo. A demanda de escuta que reconhecemos como necessária não é anterior à presença do analista na instituição, ela é produzida a por um entrelaçamento entre as redes do social $e$ as redes dos significantes. Scarparo (2008) menciona um possível caminho de trabalho no apontamento da distinção entre a noção de escuta do sujeito de direitos na cidadania e da escuta da singularidade no laço social em relação ao sujeito do inconsciente na psicanálise. Nesses termos, afirma: "É nessa 'zona de fronteira' que podemos situar uma escuta do sujeito, orientada pela ética da psicanálise" (Scarparo, 2008, p. 43).

No mesmo eixo argumentativo que privilegia a articulação da clínica com as injunções sociais, Viganò (1999) propõe uma reflexão em torno da construção da autonomia dos "usuários" nas instituições substitutivas de Saúde Mental, que é correlata ao nosso campo em discussão. Sua proposta avança na colocação de que, o ponto de partida para execução dos trabalhos voltados a esse fim perpassa pelo sentido da construção de casos que evidenciem as idiossincrasias do caso social e do caso clínico. Segundo Viganò (1999, p. 42), o caso social "é o caso do discurso do puro significante, dos instrumentos jurídicos e assistenciais", que é conduzido exclusivamente pelos operadores. O caso social na instituição da qual nos referimos trata da forma como o profissional busca e utiliza os meios normativos institucionais para solucionar determinado caso que Ihe é endereçado. Já a construção do caso clínico, vai além desse significante que já está colocado, o significante mestre da instituição. No caso clínico, quem opera é o próprio sujeito, desde que o profissional the dê condições de ser o operador. Essa passagem é fundamental também, no contexto da Assistência Social, já que é no caso clínico em que há caso social (Viganò, 1999).

O profissional de orientação psicanalítica, enquanto técnico de referência do CRAS, deve ficar atento à demanda acerca dos direitos 
sociais, esse é o objetivo primordial dessa instituição. No entanto, seu compromisso com a ética do desejo deve ser pautado na instituição. A esse respeito, temos na expressão subjetiva, por meio da teoria psicanalítica, um elemento fundamental para a construção da autonomia. É esse elemento que nos direciona. Vemos no trabalho com os aspectos subjetivos do cidadão que procura os serviços do CRAS a possibilidade de arranjos para saídas da condição de usuário em tutela. Acreditamos que tal possibilidade se fundamenta na necessidade de um espaço de escuta que coloque em evidência a posição do sujeito $(\$)$, o qual é detentor de recursos próprios na construção de um saber que solucione suas dificuldades.

\section{Referências}

Alberti, S., Figueiredo, A. C. (org.). (2006). Psicanálise e saúde mental: uma aposta (Vol. 1). Rio de Janeiro: Companhia de Freud.

Andrade Filha, Lêda L. (2013). O trabalho psicanalítico no ambulatório do Hospital Juliano Moreira: Reflexões sobre a clínica do sujeito. Tese de doutorado, Instituto de Psicologia. Universidade Federal da Bahia, Salvador, BA, Brasil.

Belo Horizonte, Secretaria Municipal Adjunta de Assistência Social. (2007). Dicionário de Termos Técnicos da Assistência Social. Belo Horizonte, MG: ASCOM.

Brasil, Ministério do Desenvolvimento Social e Combate à Fome. Secretaria Nacional de Assistência Social. (2004). Política Nacional de Assistência Social. Brasília, DF.

Brasil, Ministério do Desenvolvimento Social e Combate à Fome. Secretaria Nacional de Assistência Social. (2005). Guia de Orientação Técnica SUAS - $n^{\circ} 1$, Proteção Social Básica de Assistência Social. Brasília, DF.

Brasil, Ministério do Desenvolvimento Social e Combate à Fome. Secretaria Nacional de Assistência Social. (2009). Tipificação Nacional de Serviços Socioassistenciais. Brasília, DF.

Brasil, Ministério do Desenvolvimento Social e Combate à Fome. Secretaria Nacional de Assistência Social. (2012a). O serviço de proteção e atendimento integral à família, segundo a tipificação nacional de serviços socioassistenciais. Brasília, DF.

Brasil, Ministério do Desenvolvimento Social e Combate à Fome. Secretaria Nacional de Assistência Social. (2012b). Orientações Técnicas sobre o PAIF - Volume 1. Brasília, DF.

Brasil, Ministério do Desenvolvimento Social e Combate à Fome. Secretaria Nacional de Assistência Social. (2012c). Orientações Técnicas sobre o PAIF - Volume 2. Brasília, DF. 
Conselho Federal de Psicologia. (2007). Referências Técnicas para a Atuação do Psicólogo no CRAS/SUAS. Brasília, DF.

Dor, J. (1989). Introdução à leitura de Lacan: o inconsciente estruturado como linguagem. Porto Alegre, RS: Artes Médicas.

Dunker, C. (2013). Sobre a relação entre Teoria e Clínica em Psicanálise. In C. Dunker. A psicose na criança: tempo, linguagem e sujeito (pp. 63-73). São Paulo, SP: Zagodoni.

Figueiredo, A. C. C. (2011). Psicanálise e atenção psicossocial: clínica e intervenção no cotidiano. In Instituto APPOA. (org.). Psicanálise e Intervenções Sociais (1a. ed., Vol. 1, pp. 45-62). Porto Alegre: APPOA.

Freud, S. (1996). As perspectivas futuras da terapêutica psicanalítica. In: Edição Standard Brasileira das obras psicológicas completas de Sigmund Freud. (J. Salomão, trad., Vol. 11) Rio de Janeiro, RJ: Imago. (Texto original publicado em 1910).

Freud, S. (2006). Linhas de progresso na teoria psicanalítica. In: Edição Standard Brasileira das obras psicológicas completas de Sigmund Freud. (J. Salomão, trad., Vol. 17). Rio de Janeiro, RJ: Imago. (Texto original publicado em 1918).

Garcia-Roza, L. (2007). Freud e o inconsciente. Rio de Janeiro, RJ: Jorge Zahar. (Texto original publicado em 1984).

Lacan, J. (1988). O Seminário, livro 11: Os quatro conceitos fundamentais da psicanálise. Rio de Janeiro, RJ: Jorge Zahar. (Texto original publicado em 1964).

Lacan, J. (1998) A direção do tratamento e os princípios de seu poder. In: Escritos. Rio de Janeiro, RJ: Ed. Zahar. (Texto original publicado em 1958).

Lacan, J. (1999). O Seminário, livro 5: As formações do Inconsciente. Rio de Janeiro, RJ: Jorge Zahar. (Texto original publicado em 1957[1958]).

Lacan, J. (2008). O Seminário, Livro 7: A Ética da Psicanálise. Rio de Janeiro, RJ: Zahar. (Texto original publicado em 1959[1960]).

Lacan, J. (2009). O Seminário, Livro 1: Os escritos técnicos de Freud. Rio de Janeiro, RJ: Jorge Zahar. (Texto original publicado em 1953[1954]).

Laplanche, J., \& Pontalis, J. -B. (2001). Vocabulário de Psicanálise. São Paulo, SP: Martins Fontes.

Mariano. (2011). O praticante de psicanálise no Centro de Referência da Assistência Socia (CRAS): a intervenção retificadora e outras questões. (Dissertação de Mestrado), PUC, Belo Horizonte, MG.

Rinaldi, D. (1996). A ética da diferença: um debate entre psicanálise e antropologia. Rio de Janeiro, RJ: Eduerj/Jorge Zahar Ed.

Scarparo, M. d.-E. (2008). Em busca do sujeito perdido: a psicanálise na assistência social, limites e possibilidades. (Dissertação de Mestrado), Universidade Federal do Rio Grande do Sul, Porto Alegre, RS. 
Susin, L. M. (2012). O mal-estar na cultura e suas incidências na clínica em contexto de exclusão. Dissertação de mestrado, Programa de Pós-Graduação em Psicologia Social e Institucional, Universidade Federal do Rio Grande do Sul, Porto Alegre, RS, Brasil.

Tenório, F. R. (1999). A Psicanálise e a Clínica da Reforma Psiquiátrica. Dissertação de mestrado, Curso de Pós-graduação em Saúde Mental, Universidade Federal do Rio de Janeiro, Rio de Janeiro, RJ, Brasil.

Viganò, C. (1999). A Construção do caso clínico em Saúde Mental. In: Curinga - Psicanálise e Saúde Mental, (13), pp. 50-59.

\section{Endereço para correspondência \\ Thayane Bastos Moura Dias}

Universidade Federal de São João Del Rei

Departamento de Psicologia

Praça Dom Helvécio, 74, Dom Bosco, CEP 36301-160, São João Del Rei - MG, Brasil

Endereço eletrônico: thayanebastospsi@hotmail.com

\section{Wilson Camilo Chaves}

Universidade Federal de São João Del Rei

Departamento de Psicologia

Praça Dom Helvécio, 74, Dom Bosco, CEP 36301-160, São João Del Rei - MG, Brasil

Endereço eletrônico: camilo@ufsj.edu.br

Fuad Kyrillos Neto

Universidade Federal de São João Del Rei

Departamento de Psicologia

Praça Dom Helvécio, 74, Dom Bosco, CEP 36301-160, São João Del Rei - MG, Brasil

Endereço eletrônico: fuadneto@ufsj.edu.br

Recebido em: 08/03/2015

Reformulado em: 28/04/2016

Aceito em: 26/10/2016

\section{Notas}

* Possui graduação em Psicologia pela Universidade Federal de São João del Rei (UFSJ). Mestrado em Psicologia pelo Programa de Pós-Graduação da UFSJ.

** Licenciou-se em Filosofia pela FSFCL. Graduou-se em Psicologia pela UNIFENAS. Mestre em Filosofia e Metodologia das Ciências pela UFSCar e Doutor em Filosofia pela UFSCar. Atualmente é professor da Graduação em Psicologia e do Programa de Pós-Graduação (Mestrado) em Psicologia da UFSJ.

*** Possui graduação em Psicologia pela Universidade Federal de Minas Gerais (UFMG), mestrado em Psicologia pela Universidade São Marcos e doutorado em Psicologia (Psicologia Social) pela Pontifícia Universidade Católica de São Paulo. Concluiu o pós-doutorado no Departamento de Psicologia Clínica do Instituto de Psicologia da Universidade de São Paulo. Atualmente é professor da Graduação em Psicologia e do Programa de Pós-Graduação (Mestrado) em Psicologia da UFSJ.

${ }^{1}$ Ver: Brasil, Ministério do Desenvolvimento Social e Combate à Fome. Secretaria Nacional de Assistência Social. (2009). Tipificação Nacional de Serviços Socioassistenciais. Brasília, DF; Brasil, Ministério do Desenvolvimento Social e Combate à Fome. Secretaria Nacional de Assistência Social. (2012). O serviço de proteção e atendimento integral à família, segundo a tipificação nacional de serviços socioassistenciais. Brasília, DF; Brasil, Ministério do Desenvolvimento 
Social e Combate à Fome. Secretaria Nacional de Assistência Social. (2012). Orientações Técnicas sobre o PAIF - Volume 1 . Brasília, DF; Brasil, Ministério do Desenvolvimento Social e Combate à Fome. Secretaria Nacional de Assistência Social. (2012). Orientações Técnicas sobre o PAIF - Volume 2. Brasília, DF; Conselho Federal de Psicologia. (2007). Referências Técnicas para a Atuação do Psicólogo no CRAS/SUAS. Brasília, DF.

2 O símbolo \$ (S para sujeito, / para barrado) representa o sujeito lacaniano enquanto barrado pela linguagem, alienado no Outro, castrado. O sujeito constituído em relação ao significante.
${ }^{3} \mathrm{~d} \rightarrow \$ \vee \mathrm{a} \leftrightarrow \mathrm{i}(\mathrm{a}) \leftarrow \mathrm{m}$ (Lacan, 1957-1958/1999).
${ }^{4} \mathrm{D} \rightarrow \mathrm{A} \vee \mathrm{d} \leftrightarrow \mathrm{s}(\mathrm{A}) \leftarrow \mathrm{I}$ (Lacan, 1957-1958/1999).
${ }^{5} \Delta \rightarrow \$ \diamond \mathrm{D} \leftrightarrow \mathrm{S}\left({ }^{\mathbf{A}}\right) \leftarrow \phi($ Lacan, 1957-1958/1999). 